\title{
Genetic Diversity of Gazelles (Gazella marica and Gazella gazella) in Southeast Turkey: A Special Emphasis on Ongoing Conservation Studies of Gazella marica in Turkey*
}

\author{
Fikriye Dilan Saatoglu' ${ }^{1}$, Melis Denizci Oncu² ${ }^{\mathbb{D}}$, Hasan Emir ${ }^{3} \mathbb{D}$, Taner Hatipoglu ${ }^{3}$, \\ Sinan Can Acan ${ }^{4}$ (D) , Tolga Kankilic ${ }^{5}$ (D), Inci Togan' ${ }^{1}$, Evren Koban Bastanlar ${ }^{2,6}$ (D)
}

'Middle East Technical University, Graduate School of Natural and Applied Sciences, Department of Biological Sciences, Ankara, Turkey ${ }^{2}$ TUBITAK Marmara Research Center, Genetic Engineering and Biotechnology Institute, Gebze, Kocaeli, Turkey

${ }^{3}$ Ministry of Agriculture and Forestry, General Directorate of Nature Conservation and National Parks, Wildlife Department, Ankara, Turkey ${ }^{4}$ Middle East Technical University, Computer Center, Ankara, Turkey

${ }^{5}$ Aksaray University, Faculty of Arts and Science, Department of Biology, Aksaray, Turkey

${ }^{6}$ Ege University, Faculty of Science, Department of Biology, İzmir, Turkey

ORCID IDs of the authors: F.D.S. 0000-0003-3936-287X; M.D.O. 0000-0001-9140-1544; H.E. 0000-0002-2563-6545; T.H. 0000-0002-6010-7315; S.C.A. 0000-0002-5534-0024; T.K. 0000-0002-9058-5166; I.T. 0000-0002-2150-772X; E.K.B. $0000-0002-6296-9728$

Please cite this article as: Saatoglu FD, Denizci Oncu M, Emir H, Hatipoglu T, Acan SC, Kankilic T, Togan I, Koban Bastanlar E. Genetic Diversity of Gazelles (Gazella marica ve Gazella gazella) in Southeast Turkey: A Special Emphasis on Ongoing Conservation Studies of Gazella marica in Turkey. Eur J Biol 2019; 78(2): 88-102. DOI: 10.26650/EurJBiol.2019.0014

\section{ABSTRACT}

Objective: The genetic diversity parameters for gazelle populations sampled in Turkey were estimated to assess the effects of captive breeding on the populations' gene pools and effective population sizes.

Materials and Methods: Four individuals from a recently discovered Gazella gazella population in Hatay and two captive gazelle populations were sampled (the Kızılkuyu State Farm $(n=48)$ and the Erikçe State Farm $(n=25))$ and analyzed using nuclear DNA, mtDNA and Y-chromosome markers.

Results: The mtDNA cyt- $b$ partial sequence analysis assigned the Erikçe and Kızılkuyu samples to Gazella marica. The structure analysis differentiated significantly between them, and revealed samples originating from wild population. Both, the Y-chromosome INRA 126 locus sequences of Gazella gazella and Gazella marica males and the mtDNA partial cyt- $b$ region RFLP analysis from all the samples distinguished the two gazelle species from each other. Based on microsatellites, the estimated effective population sizes were 9.7, 8.9 and 6.4 for the Kızılkuyu, Erikçe and Hatay populations, respectively. When the Kızılkuyu and Erikçe populations (where severe inbreeding depressions seems to be occurring already) were pooled, the estimated Ne was 24.5. All these estimates were too small for the sustainability of either individual or pooled populations in the wild or even in captivity.

Conclusion: The markers used in the study provided information on two of the gazelle species (Gazella marica, and Gazella gazella): their species identity, degree of divergences, effective population sizes and the presence of admixture within the populations. These results turned out to be invaluable in terms of their contribution to future studies for the conservation of these species.

Keywords: Conservation Genetics, Biodiversity, Phylogeny, Microsatellites, mtDNA, Y-Chromosome, RFLP Analysis

* This article was derived from the MSc Thesis study completed by F. Dilan Saatoğlu in context of the TUBITAK KAMAG 109 G016 project and with the contributions from all the co-authors. 


\section{INTRODUCTION}

Gazelles belong to the genus Gazella in the Bovidae family. They are the largest and the most diverse family of ungulates (1) in the Artiodactyla order, and are distributed from Africa to Northern Asia including South-eastern Anatolia and the Arabian Peninsula (2). Due to the rapid decrease in their population sizes in the wild, many gazelle species are on the IUCN Red List of Threatened Species as reported by the IUCN/SSC Antelope Specialist Group in 2008. For this reason, conservation studies (e.g. captive breeding programs, reintroduction/introduction studies) have been initiated for various gazelle species (3).

The plains of Central and Southeastern Anatolia with hilly geographical structures as well as the climate conditions of the region are highly suitable for gazelle species to inhabit that region. Kasparek (4) reviewed the documents on the existence of gazelles in Anatolia and reported that the first known reports were from Bolvadin (Afyon), in Central Anatolia by the English surgeon William Francis Ainsworth, in 1839. Furthermore, Kasparek (4) provides documents on gazelle observations from the $19^{\text {th }}$ century addressing plains around the Adana region suggesting the existence of two different gazelle species based on their morphological differences. These two species were thought to be Gazella dorcas (an African species) and Gazella subgutturosa (mainly distributed in the western Asia and the northern Arabian Peninsula). Yet, Kumerloeve et al. (5) suggested that one of these species should have been Gazella gazella, a dominant species of the Levantin and the Arabic Peninsula, not the Dorcas Gazelle (Gazelle dorcas), as there is no evidence that they spread further than Lebanon. Moreover, Kumerloeve $(6,7)$ suggested that gazelles were distributed in the area between the border of Turkey-Syria and the Northern plains of Şanlıurfa, and they reported gazelle observations especially around Ceylanpınar. Having worked in the field, Turan (8) defined the distribution of the gazelles from Northern Hatay (Kırıkhan) to Şırnak (Cizre), which corresponds the south-eastern border of Turkey. Although Turan (8) identified the gazelle species he observed as Gazella subgutturosa, he had his suspicions about the presence of another gazelle species, Gazella dorcas, in the same region. Yet, he did not reject Kumerloeve's view on the distribution of Dorcas gazelles. Lastly, he reported previous sightings of gazelles in Iğdır, Eastern Anatolia.

There are karyotypic (9) and habitat preference studies (10) on gazelles around Şanlıurfa. Morphological studies grouped Anatolian gazelles into Gazella subgutturosa species (4, 6-8, 10-14). However, a phylogenetic study based on mitochondrial DNA (mtDNA) cytochrome $b$ gene $(c y t-b)$ sequence has shown the existence of another gazelle species, the Mountain Gazelle (Gazella gazella), in Kırıkhan, Hatay (see Figure 1) (15). Furthermore, based on mtDNA cyt- $b$ sequence analysis, they (15) grouped Southeast Anatolian gazelles as Gazella subgutturosa marica not as Gazella subgutturosa, as suggested by Wronski et al. (16). Throughout the text, we referred to this species as Gazella marica, rather than Gazella subgutturosa marica since it was shown to be phylogenetically more closely related to the
North-African species (e.g. Gazella cuvieri and Gazella leptoceros) based on the sequence analyses of the mtDNA cytochrome $b$ gene. They emphasized considering Gazella marica as a separate species due to the fact that misidentifications in conservation studies would lead to severe consequences (17, 18). For example; studies based on mtDNA cyt-b and D-loop sequences pinpointed the possible existence of reciprocally monophyletic lineages of two Gazella gazella populations $(19,20)$. Moreover, one of these populations was found to be confined to a restricted region on the Golan Heights. Therefore, in terms of conservation purposes, this population confined in a small area can be treated as a separate species.

Among the mammal species, there seems to be more complexity in the genus Gazella, and the number of studies is low $(21,22)$. There are still unsolved conflicts in their taxonomy based on morphometric, phenotypic and genetic data (23). Table 1 below describes the common names and the scientific names for the extinct and extant gazelle species present in the literature. It also summarizes the geographical distribution of these gazelle species in the old continents.

Table 1. Distribution and common names of Anatolian gazelles: those which existed in the past or exist currently

\begin{tabular}{|c|c|c|}
\hline Common Name(s) & Scientific Name & Distribution Area \\
\hline Dorcas Gazelle & Gazella dorcas & $\begin{array}{c}\text { Sahelo-Saharan } \\
\text { Region, } \\
\text { Southern Israel, } \\
\text { Syria, } \\
\text { Jordan }\end{array}$ \\
\hline $\begin{array}{l}\text { Mountain Gazelle } \\
\text { Idmi } \\
\text { Arabian Gazelle }\end{array}$ & Gazella gazella & $\begin{array}{l}\text { Mountains near } \\
\text { the Coastal Area } \\
\text { of South-eastern } \\
\text { Turkey, Lebanon, } \\
\text { Palestine, Golan, } \\
\text { Western Jordan }\end{array}$ \\
\hline $\begin{array}{l}\text { Persian Gazelle } \\
\text { Goitered Gazelle } \\
\text { Black-tailed Gazelle }\end{array}$ & $\begin{array}{c}\text { Gazella } \\
\text { subgutturosa }\end{array}$ & $\begin{array}{c}\text { Tigris/Euphrates } \\
\text { Basin, } \\
\text { Caucasus, Iran, } \\
\text { Turkmenistan, } \\
\text { China, Mongolia }\end{array}$ \\
\hline $\begin{array}{l}\text { Sand Gazelle } \\
\text { Reem/Rheem } \\
\text { Arabian Sand } \\
\text { Gazelle }\end{array}$ & $\begin{array}{l}\text { Gazella marical } \\
\text { Gazella s. marica }\end{array}$ & $\begin{array}{c}\text { Iraq, Jordan, } \\
\text { Turkey, Syria } \\
\text { Oman, Southern } \\
\text { Arabia, United } \\
\text { Arab Emirates }\end{array}$ \\
\hline
\end{tabular}

The population sizes of Gazella marica groups are in continuous decline and there are no wild subpopulations whose size exceeds 1000 individuals. Therefore IUCN's Antelope Specialist Group declared them as "Vulnerable" based on the criteria, C2a(i). Despite the law having banned illegal hunting since 
1957, the estimated population sizes of gazelles in Ceylanpınar, Şanlıurfa saw a very sharp decline (with only approximately 300 individuals remaining out of 3000) between the years 1968 and $1978(13,24)$. Following this rapid decline, the Ceylanpınar State Farm was founded with 5 individuals from the wild in 1978 ("1" in Figure. 1). Then, the Kızılkuyu and Erikçe State Farms ("2" and " 3 " in Figure 1, respectively) were established ( $n=24$ in 1998 and $n=29$ in 1999, respectively) with individuals taken from Ceylanpınar State Farm. The last State Farm, Hekimhan ("4" in Figure 1), was founded in 2005 with 8 individuals taken from Kızılkuyu State Farm. Afterwards, Kızılkuyu State Farm received some Gazella marica stock from Ceylanpınar in 2009 ("5" in Figure 1). Moreover, Erikçe State Farm received Gazella marica stock taken from the wilds of Kızılkuyu in 2009 and 2010 ("6" in Figure 1). Meanwhile, reintroduction studies on the Kızılkuyu wild from the Kızılkuyu State Farm were carried out several times between 2005 and 2014. Based on the records of the Ministry of Agriculture and Forestry (hereafter to be referred to as the Ministry), the death of juveniles can occur especially in the cold winter seasons on the state farms, even though feeding supplements are always provided.

In this study, samples taken from two captive Gazella marica populations were analyzed based on 17 autosomal microsatellite loci, partial mtDNA $c y t-b$ region and one
Y-chromosome SSR locus (INRA126) sequencing. In addition, four individuals from the Gazella gazella population in Kırıkhan, Hatay were analyzed based on the same markers. The study objectives were as follows:

(i) Estimation of the genetic diversity within and between gazelle populations to evaluate the effects of captivebreeding on both populations in terms of their gene pools and effective population sizes in order to help developing conservation strategies for these populations.

(ii) To confirm the presence of both species, Gazella marica and Gazella gazella, in the Southeastern Anatolia based on the mtDNA cyt- $b$ sequences of the samples collected independent of the previous studies.

(iii) To identify the endonucleases to be used in the Restriction Fragment Length Polymorphism (RFLP) analysis of mtDNA $c y t-b$ fragments as a quick method to discriminate between the two gazelle species of Anatolia.

(iv) Analyzing the diversity among two gazelle species based on a Y chromosome SSR locus, to be carried out for the first time in current literature.

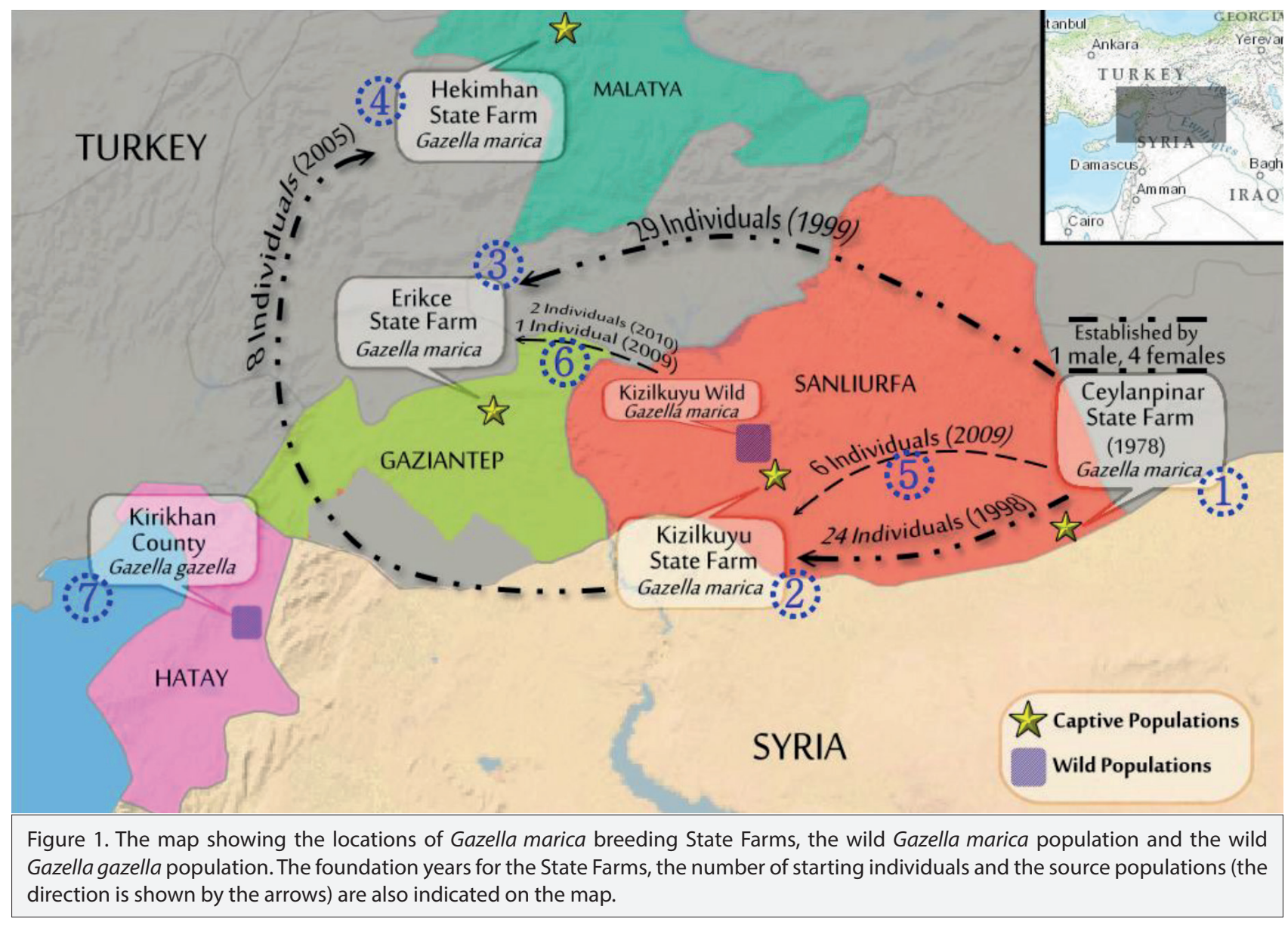


The Ministry's plan for Erikçe State Farm is to transfer all the Gazella marica individuals to Aralık and establish a wild selfsustaining Gazella gazella population there. All the first group of individuals $(n=25)$ introduced to Aralık (lğdır) were genetically analyzed in the present study. The results of the present study will be the springboard for a long term monitoring study on the re-introduced Iğdır population.

\section{MATERIALS AND METHODS}

The blood and tissue samples were collected with the approval of the Selçuk University Veterinary Faculty Ethics Committee (permit number: 2009/041) and were collected by the GDNPNP.

\section{Samples and DNA Extraction}

A total of 77 individuals were sampled (blood samples collected in $10 \mathrm{ml}$ vacuum tubes containing $\mathrm{K}_{3}$ EDTA and/or tissue samples collected in ethanol) from wild-living Gazella gazella, and captive Gazella marica populations by the Ministry and sent to our laboratory. Gazella marica samples came from two different locations: Kızılkuyu ( $n=48$; State Farm and wild population in total) and Erikçe State Farm $(n=25)$. The samples from the Kızılkuyu wild population were from individuals shot by licensed hunters during hunting seasons. Only four samples in the present study belonged to the Gazella gazella species (Kırıkhan, Hatay) provided by

\begin{tabular}{|c|c|c|c|}
\hline Loci & Primer 5'-3' & Source of Loci & Reference \\
\hline \multirow[t]{2}{*}{$R T 1$} & TGCCTTCTTTCATCCAACAA & Caribou & 27 \\
\hline & САТСТТСССАТССТСТТТАС & & \\
\hline \multirow[t]{2}{*}{ ETH10 } & GTTCAGGACTGGCCCTGCTAACA & Bovine & 28 \\
\hline & ССTCCAGCCСАСTTTCTCTTCTC & & \\
\hline \multirow[t]{2}{*}{ OarFCB304 } & CCCTAGGAGCTTTCAATAAAGAATCGG & Ovine & 29 \\
\hline & CGCTGCTGTCAACTGGGTCAGGG & & \\
\hline \multirow[t]{2}{*}{ MM12 } & CAAGACAGGTGTTTCAATCT & Bovine & 30 \\
\hline & ATCGACTCTGGGGATGATGT & & \\
\hline \multirow[t]{2}{*}{$B M 848$} & TGGTTGGAAGGAAAACTTGG & Bovine & 31 \\
\hline & СССTCTGCTCCTCAAGACAC & & \\
\hline \multirow[t]{2}{*}{ BMC1009 } & GCACCAGCAGAGAGGACATT & Bovine & 32 \\
\hline & ACCGGCTATTGTCCATCTTG & & \\
\hline \multirow[t]{2}{*}{ INRA40 } & TCAGTCTCCAGGAGAGAAAAC & Bovine & 33 \\
\hline & CTCTGCCCTGGGGATGATTG & & \\
\hline \multirow[t]{2}{*}{ IDVGA29 } & CCCACAAGGTTATCTATCTCCAG & Bovine & 34 \\
\hline & CCAAGAAGGTCCAAAGCATCCAC & & \\
\hline \multirow[t]{2}{*}{$B M 4505$} & TTATCTTGGCTTCTGGGTGC & Bovine & 31 \\
\hline & ATCTTCACTTGGGATGCAGG & & \\
\hline \multirow[t]{2}{*}{ ETH152 } & TACTCGTAGGGCAGGCTGCCTG & Bovine & 35 \\
\hline & GAGACCTCAGGGTTGGTGATCAG & & \\
\hline \multirow[t]{2}{*}{ INRABERN172 } & ССАСТTСССТGTATССТССТ & Goat & 36 \\
\hline & GGTGCTCCCATTGTGTAGAC & & \\
\hline \multirow[t]{2}{*}{ TGLA122 } & СССTCCTCCAGGTAAATCAGC & Bovine & 37 \\
\hline & AATCACATGGCAAATAAGTACATAC & & \\
\hline \multirow[t]{2}{*}{ ILSTSO05 } & GGAAGCAATGAAATCTATAGCC & Bovine & 38 \\
\hline & TGTTCTGTGAGTTTGTAAGC & & \\
\hline \multirow[t]{2}{*}{ BM757 } & TGGAAACAATGTAAACCTGGG & Bovine & 31 \\
\hline & TTGAGCCACCAAGGAACC & & \\
\hline \multirow[t]{2}{*}{ BM143 } & ACCTGGGAAGCCTCCATATC & Bovine & 31 \\
\hline & CTGCAGGCAGATTCTTTATCG & & \\
\hline \multirow[t]{2}{*}{ CSSM39 } & AATCGGAACCTAGAATATTTTGAG & Bovine & 39 \\
\hline & AGATAAAATGTGAGTGTGGTCTCC & & \\
\hline \multirow[t]{2}{*}{ CSSM43 } & AAAACTCTGGGAACTTGAAAACTA & Bovine & 39 \\
\hline & GTTACAAATTTAAGAGACAGAGTT & & \\
\hline
\end{tabular}


the locals in 2013-2014. The DNAs were extracted from blood samples using the standard phenol:chloroform:isoamyl alcohol method (25:24:1) (25). The DNAs from tissue samples were extracted using the CTAB method adapted from Winnepenninckx et al (26) at TUBITAK MRC laboratories. Stock DNA samples were stored at $-20^{\circ} \mathrm{C}$, diluted DNA aliquots were stored at $+4^{\circ} \mathrm{C}$ for short-term use.

\section{Microsatellite DNA Analysis}

Seventeen microsatellite loci chosen from the literature (Table 2) were PCR amplified. After being checked by agarose gel electrophoresis (1\%, 1XTAE), the PCR products were genotyped using the Beckman Coulter CEQ8800 Genetic Analysis System based on capillary electrophoresis.

The genotypic data was first analysed for possible genotyping errors during the experimental stage (e.g. the existence of null alleles, short allele dominance) using MICRO-CHECKER 2.2.3 software (40). In addition, Linkage Disequilibrium (LD) was tested (settings: 10.000 Markov Chain, 1.000 dememorization steps and 5.000 number of batches) using the Arlequin v.3.5.1.3. software (41).

The expected and observed heterozygosity ( $\mathrm{He}, \mathrm{Ho}$ ) parameters as well as deviations from the Hardy-Weinberg Equlibirum (HWE) were calculated using Arlequin v.3.5.1.3 software (41). The allelic richness per locus was estimated using the FSTAT V.2.9.3 package program (42) and the allelic richness of the populations was tested for significance using the Wilcoxon-Signed rank test (43). The Polymorphism Information Content (PIC) for each locus was estimated using CERVUS 3.0 (44). Moreover, the within and among population differentiations based on F-statistics (45) were analyzed using the FSTAT V.2.9.3 package program (42). For assessing any possible genetic admixture, STRUCTURE v2.3.4 (46) was used (settings: 10.000 burn-in, $\mathrm{K}=2-7$ with 10 iterations). Both Evanno et al.'s (47) and Tapio et al.'s (48) methods were employed for estimating the most likely $\mathrm{K}$ value, representing the number of differing gene pools. Furthermore, similarity coefficients were obtained by CLUMPP v1.1.2 (49) and Distruct v1.1 (50) was used to display the graphic results obtained from STRUCTURE Software. Lastly, Effective Population Size $\left(\mathrm{N}_{\mathrm{e}}\right)$ was estimated using Ne Estimator V.2.01 (51) for the gazelle populations in the present study.

\section{mtDNA Cytochrome b (cyt-b) Region}

The partial cyt- $b$ region was amplified by the primers $L 14724$ : 5'-CGAAGCTTGATATGAAAAACCATCGTTG-3' (52) and H15149:
5'-AAACTGCAGCCCCTCAGAATGATATTTGTCCTCA-3' (53). Then, $P C R$ amplicons were bidirectionally sequenced using the same PCR primers. The sequencing reactions were prepared using Beckman Coulter's GenomeLab Dye Terminator Cycle Sequencing Quick Start Kit. Afterwards, the PCR products were first ethanol precipitated, and then the chromatograms were collected by capillary electrophoresis on the Beckman Coulter CEQ8800 Genetic Analysis System. The sequences were read by the Sequencing Analysis program implemented within the system. The chromatograms were checked and individual contigs were obtained by ChromasPro software (http://www.technelysium.com.au/ChromasPro.html). After exporting the consensus sequences obtained from the contigs in FASTA format, the sequences were aligned, edited and trimmed using BioEdit software version 7.2.5 (54) for further statistical analysis. Based on this data, first, the best nucleotide substitution model was detected as Kimura 2 Parameter with gamma distribution $(\mathrm{G}=0.23)$ and then a Neighbor joining (NJ) tree was constructed with 1000 bootstrap values using software MEGA version 6.06 (55). Finally, after examining the sequences for possible RFLP, these partial mtDNA cyt- $b$ gene PCR products were cut by two restriction endonucleases (Haelll, Hinfl), which had been suggested for distinguishing between the gazelle species (18).

\section{Y-Chromosome Analysis}

Two microsatellite loci (Table 3) situated on the Y- chromosome were amplified by PCR and then the purified PCR products were sent to the private RefGen Company (http://www.refgen.com/) for Sanger sequencing using the platform ABI PRISM ${ }^{\circledast} 3100$ Genetic Analyzer System.

\section{Estimating Life Parameters}

The birth and death rates for the State farms were estimated using the data provided by the Ministry to gain a general idea about their current trend as both of these parameters are affected by inbreeding in captive populations. The birthing period for gazelles is from April to the end of May. To calculate the birth rate; first the populations' sizes were estimated before and after the birthing period. Then the absolute difference between these population sizes was taken. Finally, this number (the difference) was divided into the number of females present before the birth. Moreover, the death rate was calculated by dividing the number of deaths into the census size of the populations including newborns of that year. The trends in these estimated parameters were compared with the other findings of the present study.

Table 3. The Y-chromosome microsatellite loci used in the study: the primer sequences, the source organism and related references

\begin{tabular}{lccc}
\hline Loci & Primer $\mathbf{5}^{\prime} \mathbf{- 3} \mathbf{3}^{\prime}$ & Source Organism & Reference \\
\hline INRA126 & GTTGTTGCCTCTGCAGAGTAGG & Bovine & 33 \\
\hline UMN0103 & GACACTCTTTCTATTTTCAAGG & & \\
\hline & ACACAGAGTATTCACCTGAG & Bovine & 56 \\
\hline
\end{tabular}




\section{RESULTS}

\section{Genetic Variation Based on Microsatellite Loci}

Among the 17 microsatellite markers, BM143 and CSSM39 had the lowest number of alleles, whereas INRA40 and OarFCB304 had the highest. The observed allele ranges and the number of observed alleles per population for each locus are given in Table 4.

Table 4. The allele ranges for each loci and the number of alleles per locus per population observed in the study

\begin{tabular}{lccccc}
\hline Locus / Pop. & $\begin{array}{c}\text { Allele } \\
\text { Range }\end{array}$ & $\begin{array}{c}\text { Kizılkuyu } \\
\text { (n:48) }\end{array}$ & $\begin{array}{c}\text { Erikçe } \\
\text { (n:25) }\end{array}$ & Total & $\begin{array}{c}\text { Hatay } \\
\text { (n:4) }\end{array}$ \\
\hline RT1 & $196-200$ & 3 & 3 & 3 & 2 \\
\hline ETH10 & $213-245$ & 10 & 8 & 10 & 6 \\
\hline OARFCB304 & $144-174$ & 10 & 9 & 12 & 4 \\
\hline MM12 & $79-81$ & 2 & 2 & 2 & 2 \\
\hline BM848 & $207-229$ & 5 & 5 & 6 & 2 \\
\hline BMC1009 & $274-300$ & 8 & 5 & 8 & 4 \\
\hline INRA40 & $201-297$ & 12 & 7 & 12 & 5 \\
\hline IDVGA29 & $99-132$ & 3 & 1 & 3 & 5 \\
\hline BM4505 & $196-254$ & 10 & 5 & 10 & 1 \\
\hline ETH152 & $192-210$ & 1 & 1 & 1 & 5 \\
\hline INRABERN172 & $229-251$ & 8 & 6 & 9 & 5 \\
\hline TGLA122 & $122-126$ & 3 & 3 & 3 & 3 \\
\hline ILSTS005 & $179-195$ & 5 & 3 & 6 & 6 \\
\hline BM757 & $159-201$ & 4 & 2 & 4 & 2 \\
\hline BM143 & $84-114$ & 1 & 1 & 1 & 1 \\
\hline CSSM39 & $177-183$ & 1 & 2 & 2 & 1 \\
\hline CSSM43 & $246-264$ & 9 & 7 & 9 & 4 \\
\hline & & & & & \\
\hline
\end{tabular}

\section{Presence of null alleles and LD}

There was a signal indicating the possibility of null allele in the Kızılkuyu population for the locus IDVGA29 when the data was analyzed using MICROCHECKER 2.2.3 software (40). Therefore, this locus was excluded from further analysis. Linkage Disequilibrium analysis with Bonferroni Correction for the pairwise comparisons of the remaining 16 loci within the study populations did not result in a significant deviation. In addition, there was no significant deviation from the HWE detected in any locus in any population.

\section{Diversity Estimates and Allelic Richness}

The average expected heterozygosity per locus per population was calculated as 0.69 for the Kızılkuyu Gazella marica population, 0.63 for the Erikçe Gazella marica population and 0.602 for the Hatay Gazella gazella population. The average observed and expected heterozygosity estimates per locus per population and overall averages are given in Table 5.
For the Kızılkuyu population, thirteen out of sixteen allelic richness (AR) estimates were equal to or slightly higher than the Erikçe population, and when tested, a significant difference was detected between the Kızılkuyu and Erikçe populations $(p<0.05)$ using the Wilcoxon-Signed rank test (43) based on AR estimates. The average maximum and minimum mean allelic richness estimates among the loci analysed were 9.338 for OarFCB304, and 1.000 for both ETH152 and BM143. In addition, the most informative locus based on PIC estimates was ETH10 (0.801) and the least informative ones were ETH152 and BM143 (0.000). As larger samples are expected to have more alleles, a rarefaction algorithm was employed in these estimates to correct for sample size differences.

The pairwise $F_{S T}$ measures were estimated for three of the populations (Kızılkuyu, Erikçe and Hatay) and the pairwise genetic differentiation between the study populations was found to be statistically significant $(p<0.01$, see Table 6$)$ after applying permutation tests with Bonferroni Correction. However, it must be noted that the pairwise $\mathrm{F}_{S T}$ estimate for the Kızılkuyu and Erikçe populations (0.0444) is <0.05; therefore, it can be considered as "non-significant" when Wright's scale (57) is applied since it interprets $F_{S T}$ estimates as non-significant for values $<0.05$, significant for values between 0.05 and 0.25 , and highly significant for values $>0.25$.

\section{Structure Analysis}

The genotypic data was run on STRUCTURE v2.3.4 (46) software using these settings: 10.000 burn-in, $\mathrm{K}=2-7$, and 10 iterations. First, the most likely $\mathrm{K}$ value was estimated using the Delta $\mathrm{K}$ method (47). The results suggested that the most likely number of genetic groups is $\mathrm{K}=3$. The similarity test (48) run by CLUMPP software (49) revealed two probable $\mathrm{K}$ values ( 2 and 4) as the constructed graphics revealed two highest peaks for $\mathrm{H}^{\prime}$. Afterwards, the microsatellite data was run on STRUCTURE software again by setting the K parameter as "2-4", and the resulting graphics were displayed by DISTRUCT software (Figure 2). When $\mathrm{K}=2$, the individuals were grouped with respect to their origin of species: Gazella gazelle and Gazella marica. When $\mathrm{K}=3$, a genetic heterogeneity was detected between the individuals of the Gazella marica populations. However, differentiation between the two Gazella marica populations of Kızılkuyu and Erikçe (Figure 2) are evident with $\mathrm{K}=4$. The four major components in the three populations were depicted by blue, purple, red and green. Blue is exclusively associated with the Hatay population (Gazella gazella). Kızılkuyu seemed to be represented mainly by purple whereas green is associated mainly with Erikçe.

When $\mathrm{K}=4$, there were a few differentiated individuals (depicted in red) present in the Gazella marica populations, but mostly in the Kızılkuyu population, which were indicated with numbers (3-10, 12 and 13) (Figure 2). All these individuals (3-10, 12 and 13) have more than $30 \%$ of the genetic component displayed in red. According to the records provided by the Ministry, most of these numbered individuals ( 1 to 8 and 10 to 12) were hunted individuals from the wild Kızılkuyu population. Therefore, it can be anticipated that the red color may, in general, be 
Table 5. The average expected and observed heterozygosity (He, Ho) parameters estimated per locus per population and average estimates per population as found in the study

\begin{tabular}{|c|c|c|c|c|c|c|}
\hline \multirow[t]{2}{*}{ Locus } & \multicolumn{2}{|c|}{ Kızılkuyu (n:48) } & \multicolumn{2}{|c|}{ Erikçe (n:25) } & \multicolumn{2}{|c|}{ Hatay (n:4) } \\
\hline & $\mathrm{He}$ & Ho & $\mathrm{He}$ & Ho & $\mathrm{He}$ & Ho \\
\hline RT1 & 0.516 & 0.5 & 0.581 & 0.64 & \multicolumn{2}{|c|}{ Monomorphic } \\
\hline ETH10 & 0.846 & 0.813 & 0.825 & 0.88 & 0.857 & 1 \\
\hline OARFCB304 & 0.840 & 0.729 & 0.786 & 0.76 & \multicolumn{2}{|c|}{ Monomorphic } \\
\hline MM12 & 0.379 & 0.375 & 0.444 & 0.32 & \multicolumn{2}{|c|}{ Monomorphic } \\
\hline BM848 & 0.654 & 0.625 & 0.692 & 0.64 & 0.679 & 0.5 \\
\hline BMC1009 & 0.803 & 0.851 & 0.776 & 0.88 & 0.536 & 0.75 \\
\hline INRA40 & 0.850 & 0.792 & 0.812 & 0.72 & \multicolumn{2}{|c|}{ Monomorphic } \\
\hline BM4505 & 0.768 & 0.666 & 0.573 & 0.6 & \multicolumn{2}{|c|}{ Monomorphic } \\
\hline ETH152 & \multicolumn{2}{|c|}{ Monomorphic } & \multicolumn{2}{|c|}{ Monomorphic } & 0.571 & 0 \\
\hline INRABERN172 & 0.719 & 0.813 & 0.816 & 0.96 & 0.429 & 0.5 \\
\hline TGLA122 & 0.651 & 0.681 & 0.492 & 0.64 & \multicolumn{2}{|c|}{ Monomorphic } \\
\hline ILSTS005 & 0.522 & 0.458 & 0.605 & 0.64 & 0.571 & 0.5 \\
\hline BM757 & 0.551 & 0.583 & 0.510 & 0.44 & \multicolumn{2}{|c|}{ Monomorphic } \\
\hline BM143 & \multicolumn{2}{|c|}{ Monomorphic } & \multicolumn{2}{|c|}{ Monomorphic } & 0.571 & 1 \\
\hline CSSM39 & \multicolumn{2}{|c|}{ Monomorphic } & 0.115 & 0.12 & \multicolumn{2}{|c|}{ Monomorphic } \\
\hline CSSM43 & 0.844 & 0.792 & 0.802 & 0.76 & \multicolumn{2}{|c|}{ Monomorphic } \\
\hline $\begin{array}{l}\text { Population } \\
\text { Average }\end{array}$ & 0.69 & 0.6675 & 0.6304 & 0.6429 & 0.602 & 0.6071 \\
\hline
\end{tabular}

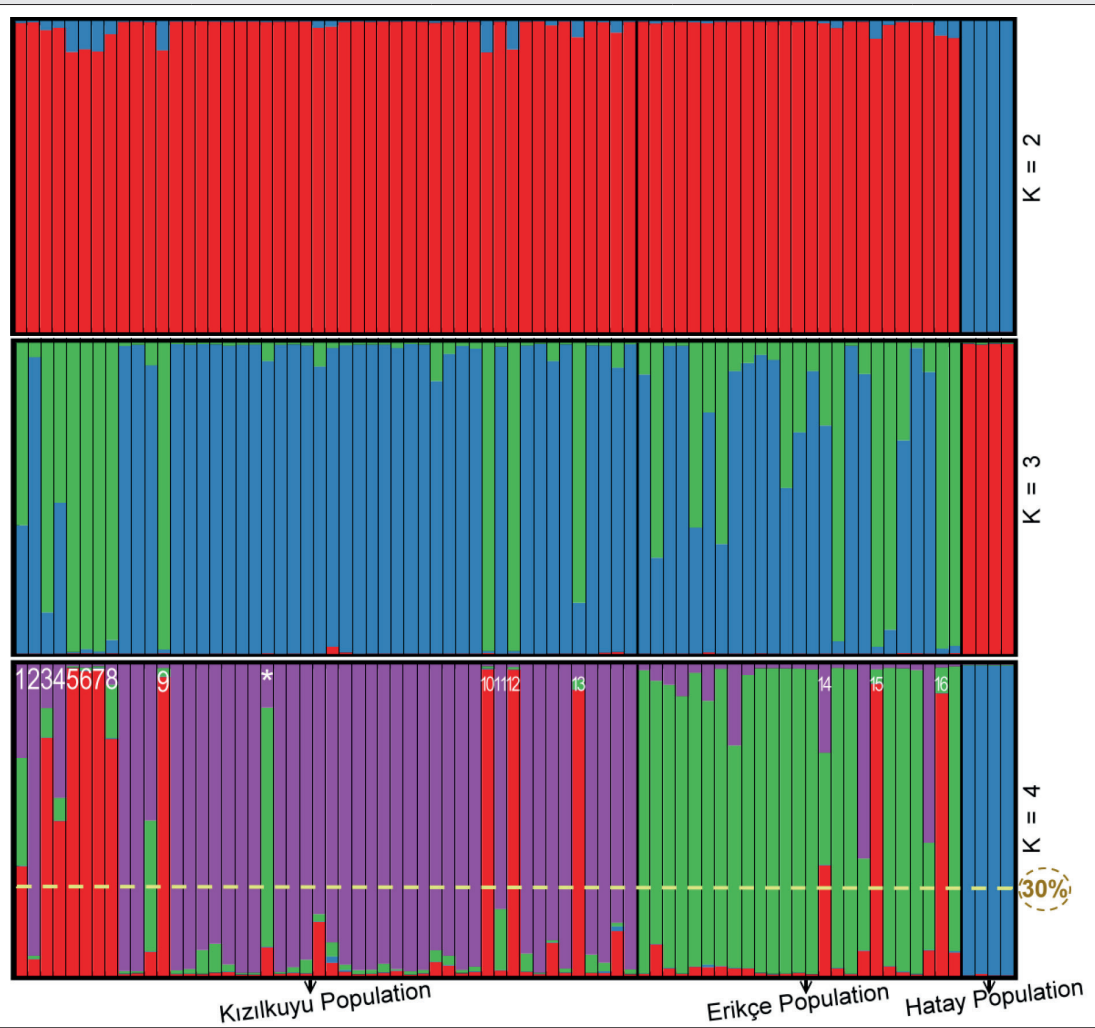

Figure 2. An admixture analysis of the three populations was obtained using the software STRUCTURE v2.3.4 (45). Each individual is represented by a bar plot in the figure above. For $\mathrm{K}=4$, the genetic components within individuals are represented by 4 colors: Purple, green, red and blue. The numbered individuals from 1 to 8 and from 10 to 12 in the Kızılkuyu population are hunted individuals from the wild Kızılkuyu population based on the information provided by the Ministry. The individual from Kızılkuyu population indicated by a star is heavily represented by ( 75\%) a green color. The numbered individuals from the Erikçe population (14-16) (those exhibiting more than $30 \%$ of their genetic component) were depicted in red. 
Table 6. Pairwise FST estimates (above the diagonal) with $\mathrm{p}$ values (below the diagonal) based on 3000 permutations and Bonferroni corrections

\begin{tabular}{lccc}
\hline Pairwise FST & $\begin{array}{c}\text { Kızılkuyu } \\
(\mathbf{n : 4 8 )}\end{array}$ & Erikçe (n:25) & Hatay (n:4) \\
\hline Kızılkuyu (n:48) & & $* *$ & $* *$ \\
\hline Erikçe (n:25) & 0.0444 & & $* *$ \\
\hline Hatay (n:4) & 0.4378 & 0.4588 & \\
\hline$\left(p^{* *}<0.01\right)$ & & & \\
\hline
\end{tabular}

marking the individuals from the Kızılkuyu wild population. On the other hand, the individual indicated with a star in the Kızılkuyu population exhibited mostly ( 75\%) a green color. Thus, it seems to be more similar to members of the Erikçe population than to those of the Kızılkuyu population. Moreover, the numbered individuals in the Erikçe population (14-16) had a genetic component (>30\%) displayed in red associated with the wild Kızılkuyu members, suggesting that these individuals had their origins in the wild Kızılkuyu population.

\section{Effective Population Size Estimation}

The effective population sizes were estimated as 9.7 for the Kızılkuyu population (Gazella marica, $n=48$ ), 8.9 for the Erikçe population (Gazella marica, $\mathrm{n}=25$ ) and 6.4 for the Hatay population (Gazella gazella, $\mathrm{n}=4$ ). When we pooled the Kızılkuyu and Erikçe populations, the estimated $\mathrm{N}_{\mathrm{e}}$ was 24.5. Furthermore, we re-estimated $\mathrm{N}_{\mathrm{e}}$ for the Kızılkuyu population after removing the individuals reported as hunted due to the possibility that they might have originated from the Kızılkuyu wild region rather than from the state farm, which decreased from 9.7 to 8.9 .

\section{Sequence Variation at Partial mtDNA Cyt-b Gene}

The mtDNA cyt- $b$ partial fragments (381 bp long) of 77 individuals were successfully amplified and sequenced. No polymorphisms were found within this $381 \mathrm{bp}$ region based on sequences either within or between the populations of the Gazella marica samples; nor were any polymorphisms detected within the Gazella gazella sample $(n=4)$. However, these two species (Gazella marica and Gazella gazella) were found to be different at 23 sites out of the 381 bp region that was analyzed. The sequences were employed in the construction of an NJ tree (Figure 3), where sequences of the different gazelle species taken from the GenBank (Table 7) were also included.

According to the phylogenetic tree, reconstructed based on the partial mtDNA cyt- $b$ sequences ( Figure 3):

1. Hatay samples were included in the Gazella gazella cluster confirming the results of Kankılıç et al. (15).

2. Ceylanpınar State Farm originated individuals were grouped with those individuals once called Gazella subgutrosa marica, but now called Gazella marica (16).
3. Compared to the present day Arabian Peninsula (Oman and Iraq) samples contained in this pylogenetic tree, some genetic variation was observed among the individuals of the Gazella marica species.

As a consequence, based on the mtDNA cyt- $b$ sequences analyzed in this study, the existence of two different species (Gazella marica and Gazella gazelle) within the borders of Turkey was confirmed.

\section{“RFLP Analysis” as a Quick and Cheap Species Identification Method}

The restriction enzymes, Haelll and Hinfl did not exhibit any polymorphism within or between the Gazella marica populations nor within the Gazella gazella sample as expected from the sequence analysis. However, both of the enzymes' restriction profiles discriminated between the Gazella marica and Gazella gazelle species as shown on the right margin in Figure 4.

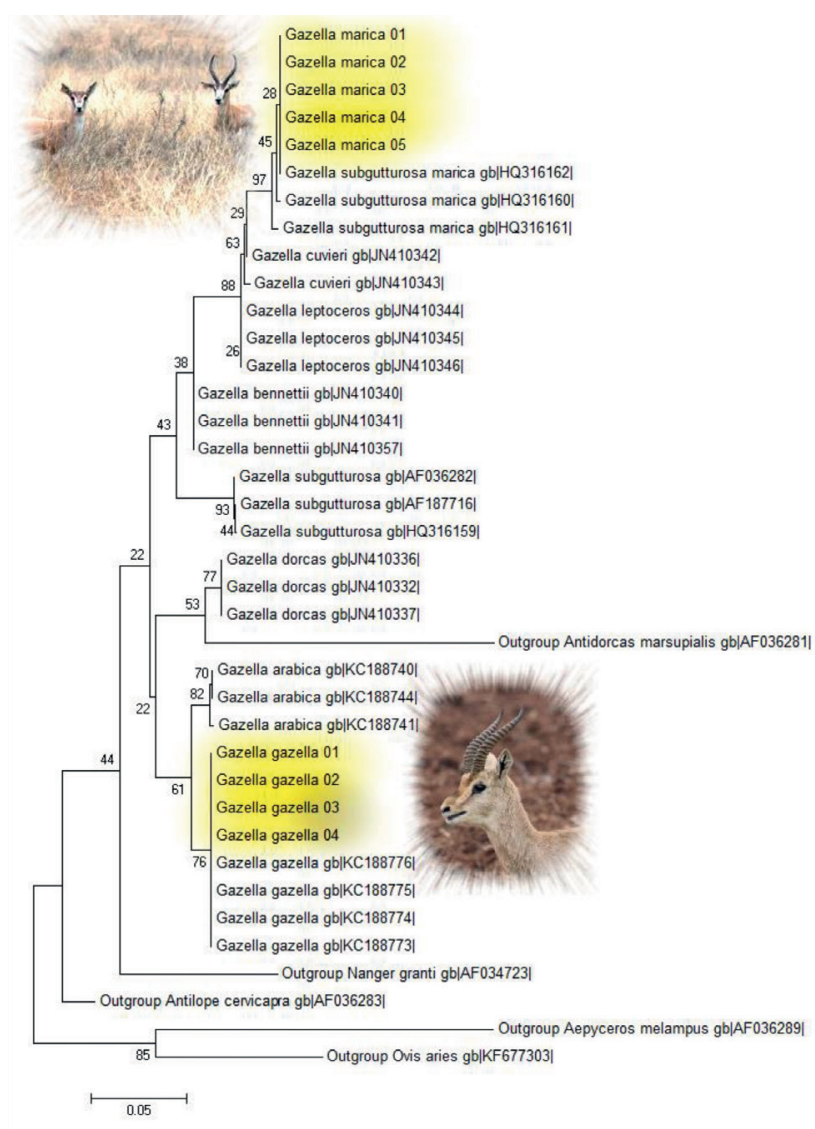

Figure 3. The phylogenetic tree constructed using an NJ algorithm with a 1000 Bootstrap value and employing a K2 nucleotide substitution model with gamma distribution $(G=0.23)$. The GenBank Accession numbers for the samples taken from the literature were given at the end of the sample names. The highlighted samples are those analyzed in the present study. The MEGA v6.06 software (54) was used for the analysis. 
Table 7. The summary of information about the samples taken from the literature. Their geographic origins (if available), their captive/wild status, accession numbers and related references are given in the table

\begin{tabular}{|c|c|c|c|c|}
\hline Species & Origin & Captive/Wild & Accession Number & Reference \\
\hline G. arabica & Southern Arava Valley, Israel & Wild & KC188740 & 60 \\
\hline G. arabica & Southern Arava Valley, Israel & Wild & KC188741 & 60 \\
\hline G. arabica & Southern Arava Valley, Israel & Wild & KC188744 & 60 \\
\hline G. bennettii & KKWRC, Thumamah & Captive & JN410340 & 20 \\
\hline G. bennettii & KKWRC, Thumamah & Captive & JN410341 & 20 \\
\hline G. bennettii & KKWRC, Thumamah & Captive & JN410357 & 20 \\
\hline G. cuvieri & EEZA, Almeria & Captive & JN410342 & 20 \\
\hline G. cuvieri & EEZA, Almeria & Captive & JN410343 & 20 \\
\hline G. dorcas & KKWRC, Thumamah & Captive & JN410332 & 20 \\
\hline G. dorcas & KKWRC, Thumamah & Captive & JN410336 & 20 \\
\hline G. dorcas & Tunisia & Wild & JN410337 & 20 \\
\hline G. gazella & Central Israel & Wild & KC188773 & 60 \\
\hline G. gazella & Central Israel & Wild & KC188774 & 60 \\
\hline G. gazella & Central Israel & Wild & KC188775 & 60 \\
\hline G. gazella & Central Israel & Wild & KC188776 & 60 \\
\hline G. leptoceros & Tunisia & Wild & JN410344 & 20 \\
\hline G. leptoceros & Tunisia & Wild & JN410345 & 20 \\
\hline G. leptoceros & Western Desert, Egypt & Wild & JN410346 & 20 \\
\hline G. subgutturosa & MNHN, Paris & Unspecified & AF036282 & 58 \\
\hline G. subgutturosa & Aksu, Chinese Turkistan & Wild & HQ316159 & 18 \\
\hline G. subgutturosa & Samarra, Iraq & Wild & AF187716 & 17 \\
\hline G. s. marica & Ramlat Fasad, Oman & Wild & HQ316160 & 18 \\
\hline G. s. marica & WA-SWC, United Arab Emirates & Captive & HQ316161 & 18 \\
\hline G. s. marica & Wadi Abu Al Jir, Iraq & Wild & HQ316162 & 18 \\
\hline \multicolumn{5}{|l|}{ Outgroup } \\
\hline Antidorcas marsupialis & MNHN, Paris & Unspecified & AF036281 & 58 \\
\hline Nanger granti & MNHN, Paris & Unspecified & AF034723 & 58 \\
\hline Antilope cervicapra & MNHN, Paris & Unspecified & AF036283 & 58 \\
\hline Aepyceros melampus & MNHN, Paris & Unspecified & AF036289 & 58 \\
\hline
\end{tabular}

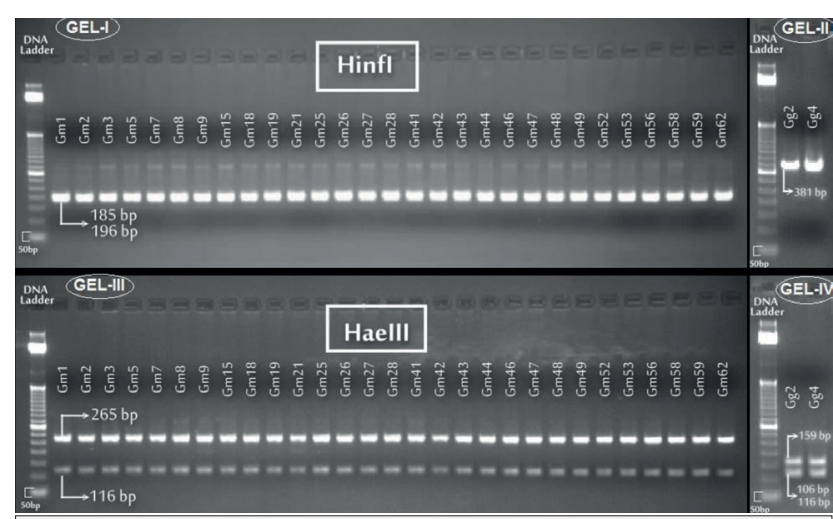

Figure 4. A sample image from the mtDNA partial cyt-b gene RFLP analysis results of the samples from two different gazelle species. The image is composed of views from four different gels as indicated in the figure and the samples are labeled: ' $G m^{\prime}$ is used for Gazella marica from Kızılkuyu (Şanlıurfa) and Erikçe (Gaziantep); 'Gg' is used for Gazella gazella (Hatay Mountain Gazelle) from Hatay.

\section{Y-Chromosome Analysis}

Two microsatellite loci on the $Y$ chromosome (UMN103, INRA126) of gazelle species were amplified. UMN103 did not produce clean sequences, but amplification and sequencing of INRA126 locus produced clean results. Two alleles were observed with a single nucleotide difference at the $216^{\text {th }}$ base (Figure 5), which differentiated between the males of the two gazelle species of the present study (Gazella gazella and Gazella marica).

\section{Life Parameters}

Captivity populations are, in general, closed populations and have low effective population sizes. Therefore, they are prone to suffer from inbreeding depression. We obtained the documents kept by the Ministry on the two captive Gazella marica populations (Kızılkuyu and Erikçe). However, there seems to be inconsistency in year-to-year census values. Nevertheless, we used these records to estimate approximate birth and death rates in these captive populations to project 


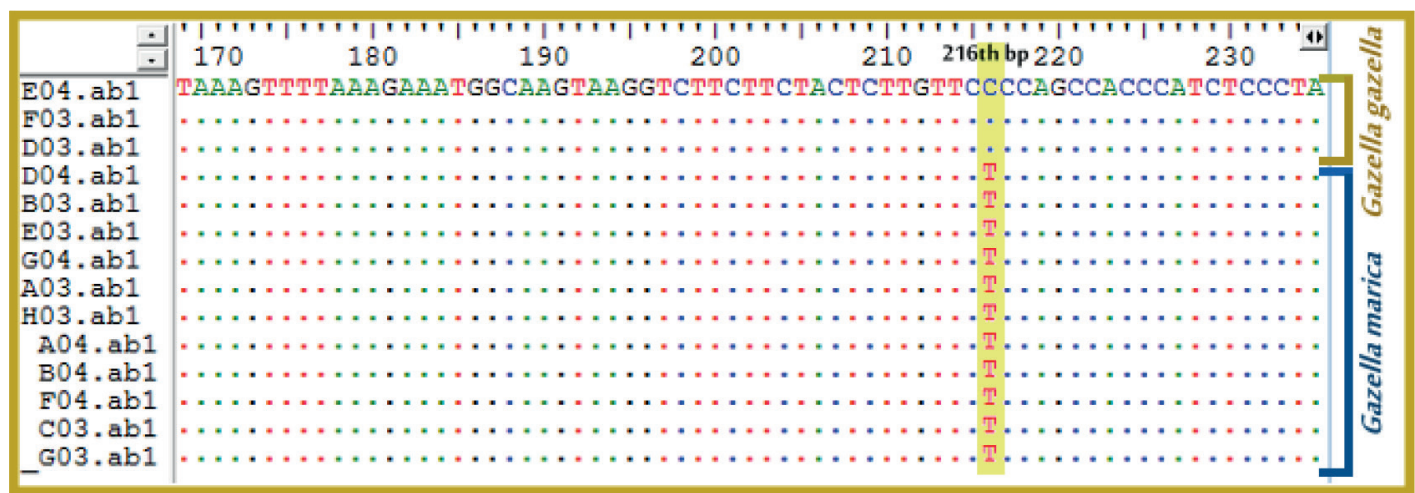

Figure 5. The alignment of the Y chromosome INRA126 locus sequences obtained in the study. Male individuals of Gazella marica and Gazella gazella showed a single base difference at the 216th bp as highlighted in yellow.

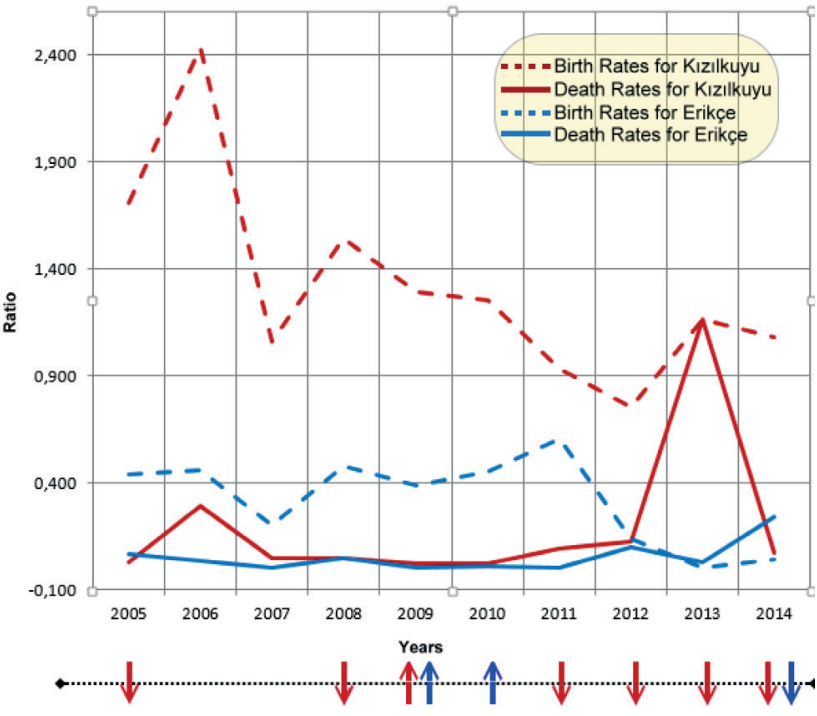

Figure 6. Approximate birth (dashed lines) and death rates (solid lines) of the Kızılkuyu (red) and Erikçe (blue) State Farm populations. The upward arrows indicate the reintroduction/ introduction practices where the individuals were taken from the state farms, whereas the downward arrows indicate those years when new individuals were introduced into the state farms.

the present trend in these populations and this graphic is presented in Figure 6.

Estimations of the life parameters for the Kızılkuyu and Erikçe populations revealed that, in general, there has been a decrease in birth rates and an increase in death rates in both of these captive populations over time. Moreover, the estimates proposed that, the Erikçe population has lower birth rates and higher death rates than the Kızılkuyu population.

\section{DISCUSSION}

Gazelles and its close relatives are contained within the Antilopinae subfamily. One of the most commonly used markers for this subfamily is the mtDNA cyt- $b$ region $(2,15$,
18-20, 59, 60). This enables comparative studies within and between gazella spp. Employing this marker in our analyses confirmed the existence of both Gazella marica and Gazella gazella species and confirmed their taxonomic status. Additionally, Haelll and Hinfl endonucleases used for the RFLP analysis of mtDNA cyt- $b$ fragments (18) produced different haplotypes and separated the Gazella marica and Gazella gazella species from each other (Figure 4). Furthermore, we retrieved the Gazella subgutturosa mtDNA cyt- $b$ sequences from the GenBank and identified their RFLP haplotypes with respect to the two endonucleases used in the study. Then, we compared the restriction profiles of the three gazelle species (Table 8).

Table 8. The restriction sites for the two restriction endonucleases; Haell and Hinfl, on the partial mtDNA cyt-b sequences of the three gazelle species are given

\begin{tabular}{|c|c|c|}
\hline $\begin{array}{l}\text { RFLP } \\
\text { Enzyme }\end{array}$ & Species & Restriction Site \\
\hline \multirow{3}{*}{ Haelll } & Gazella marica & $116^{\text {th }} \mathrm{bp}$ \\
\hline & Gazella subgutturosa & $116^{\text {th }}$ and $275^{\text {th }} \mathrm{bp}$ \\
\hline & Gazella gazella & $116^{\text {th }}$ and $275^{\text {th }} \mathrm{bp}$ \\
\hline \multirow{3}{*}{ Hinfl } & Gazella marica & $185^{\text {th }} \mathrm{bp}$ \\
\hline & Gazella subgutturosa & $185^{\text {th }}$ and $302^{\text {nd }} \mathrm{bp}$ \\
\hline & Gazella gazella & None \\
\hline
\end{tabular}

The Hinfl enzyme distinguished the three gazelle species from each other, whereas Haelll could only make a distinction between the Gazella marica and Gazella subgutturosa species. Wacher et al. (18) employed these enzymes to discriminate between Gazella marica and Gazella subgutturosa. Our results have further shown that Gazella gazella can be differentiated from the other two gazelle species based on the mtDNA cyt- $b$ RFLP analysis with Haell endonuclease. It has been reported that some individuals may look exactly like Gazella subgutturosa but carry Gazella marica type of mtDNA (59). For this reason, we propose employing L14724 and H15149 primers for the amplification of mtDNA cyt- $b$ region and then analyzing the RFLP profile of this region (using Haelll and Hinfl restriction endonucleases) as a quick and cheap method. This can solve 
the conflict differentiating between Gazella marica and Gazella subgutturosa. Furthermore, an unknown tissue sample can be analyzed using these two endonucleases for species identification if it belongs to one of these three species.

To reveal sex-linked introgression in populations, mtDNA and Y-chromosome markers should be analyzed as well as autosomal markers. The $Y$ chromosome locus, INRA126 (33), was sequenced from both Gazella gazella and Gazella marica species for the first time in literature by this study. The INRA 126 locus was chosen as it showed high polymorphism in different bovid species $(61,62)$. The results suggested that this locus can differentiate the males of these two gazelle species. However, the high number of wild samples from both of the species must be tested to confirm the discriminatory power of this sequence.

Populations with low Ne may show wild fluctuations in their allele frequencies and are expected to lose variability due to genetic drift; especially in mtDNA and $Y$ chromosome on the account of their haploid nature. We have observed one $Y$ chromosome haplotype (INRA126) and one mtDNA haplotype in the Ceylanpınar State Farm population. Since this farm started with one male, a single $Y$ choromosome haplotype was expected. However, there were more than one female in the starting population, and may be more than one mtDNA haplotype. Yet, as the founding population size was very small, with a low Ne under random drift, it might have resulted in a single haplotype for mtDNA. Twenty years after the foundation of the Ceylanpınar State Farm, individuals transferred to the Kızılkuyu and the Erikçe State Farms as founders most probably had little or no genetic variation. Therefore, it can be presumed that these two farms must have started with a very low Ne. Moreover, they probably had the same single haplotypes for both $Y$ chromosome and mtDNA present in Ceylanpınar. Therefore, its is not surprising that no variation was observed either in the mtDNA or in the $\mathrm{Y}$ chromosome sequences in these captive populations.

During the preparation stage of our study, we could not find in the literature any genetic diversity study on gazelle species based on microsatellite loci analyses. Therefore, we have analyzed 17 polymorphic loci randomly chosen among the previously studied loci of different species (bovine, ovine, goat and caribou), which were available in the literature (Table 2). Since then, six studies have been published concerning the captive and wild populations of different gazelle species, and they all utilized bovine, ovine and goat originated microsatellite loci. Among these studies, we have one common locus (OarFCB304) out of seven with Zachos et al. (63); eight common loci (BMC1009, CSSM43, BM4505, OARFCB304, BM848, INRA040, IDVGA29, CSSM39) out of twenty with Ruiz-Lopez et al. (64); four common loci (BM4505, CSSM043, INRA40, OarFCB304) out of eleven with Lerp et al. (65); four common loci (ETH10, INRA40, BM4505, TGLA122) out of nine with Hadas et al. (66); one common locus (OarFCB304) out of twelve with Duo et al. (67); two common loci (OarFCB304, CSSM043) out of ten with Okada et al. (68). We have compared our results with this recently published data. The population sample sizes varied from 11 (Acacia gazelle, 66) to 138 (Mongolian gazelle, 68) in these studies and the average number of observed alleles across the analyzed microsatellite loci changed between 3.3 (Gazella dama captive population, $n=112,64$ ) and 15 (Mongolian gazelle wild population, $\mathrm{n}=138,68$ ). Our sample sizes were $\mathrm{n}=4$ (Gazella gazella, Hatay wild population), n=48 (Gazella marica, Kızılkuyu captive and wild samples), n=25 (Gazella marica, Erikçe captive population) and the average number of observed alleles were 3.4, 5.6 and 4.1, respectively. Moreover, the average observed heterozygosity in the above-mentioned literature ranged between 0.335 (Gazella arabica Farasan Islands wild population, 65) and 0.91 (Przewalskii's gazelle Sand Island wild population, 67), whereas the average expected heterozygosity ranged between 0.353 (Acacia gazelle, 66) and 0.854 (Mongolian gazelle, 68). In our study, the average observed heterozygosity values were $0.67,0.64$ and 0.61 ; and the average expected heterozygosities were $0.69,0.63$ and 0.60 for the Kızılkuyu and Erikçe Gazella marica samples and Hatay Gazella gazella sample, respectively. Comparatively, Hadas et al. (66) reported the average He within a wild Gazella gazella population in Southern Levant as 0.616 and the average He for a wild Acacia gazelle population suffering from inbreeding depression in the same region as 0.35 based on nine microsatellite loci. Furthermore, the average He estimate based on seven microsatellite loci for a captive population of Arabian oryx was reported as 0.57 (69). Consequently, it can be said that the gene diversity ( $\mathrm{He})$ observed within the populations of the present study is as high as that of the wild gazelle populations found in the literature.

Allelic richness takes variations in the sample sizes into account, measures the genetic diversity (in terms of allele numbers at a locus) and provides information on the population's long-term potential for adaptability and persistence. The Polymorphic Information Content (PIC) parameter is estimated based on the number of alleles and their relative frequencies at a locus, which predicts the informativeness of that locus. PIC values between 0.4 and 0.7 are interpreted as being moderately informative; whereas, PIC values higher than 0.7 can be interpreted as highly informative (70). According to this information, we can state that the most informative locus was ETH10 (0.801), 6 out of 16 loci were highly informative, and 6 out of 16 loci were moderately informative. In total, twelve loci (RT1, ETH10, OARFCB304, BM848, BMC1009, INRA40, BM4505, INRABERN172, TGLA122, ILSTS005, BM757 and CSSM43) were found to be informative. Therefore, one can select from these twelve loci in future studies on gazelles to assess their genetic diversity of populations or perform pedigree analysis.

Observing a low genetic variability is not surprising in small and/or captive populations. We assessed the genetic diversity based on expected heterozygosity $\left(\mathrm{H}_{\mathrm{e}}\right)$ and allelic richness parameters, which are not affected significantly by low sample sizes. For both of the parameters the Erikçe population exhibited slightly lower estimates (average $\mathrm{H}_{\mathrm{e}}: 0.63$ and allelic richness: 4.31) than the Kızılkuyu captive population (average $H_{e}$ : 0.69, allelic richness: 5.05). The Wilcoxon-Signed rank test 
(43) based on the allelic richness estimates found a statistically significant $(p<0.05)$ difference between the Kızılkuyu and Erikçe populations. For the Hatay population, allelic richness was not considered due to its low sample size and the heterozygosity was estimated as 0.6. Subsequently, a random subpopulation of size $n=4$ (the same size as the Hatay population) was drawn from Kızılkuyu. For this subpopulation; the estimated $\mathrm{He}(0.68)$ was found to be higher than the He (0.6) estimate of the Hatay population. This results should be interpreted with care. It might be indicative of a lower genetic diversity in the Hatay population (Gazella gazella) than either of the two captive Gazella marica populations.

Gene pools of small and isolated populations can easily diverge from their source populations. The genetic drift occurring in small populations can quickly result in big changes. Kızılkuyu and Erikçe captive populations were sourced by the same population and established about 20 years ago. They may not be strictly isolated, but they must have diverged due to random drift, for about 10-12 generations (generation time of gazelle was assumed as 1 or 2 years). That is why, we have observed a significant $(p<0.01)$ pairwise $F_{S T}$ value $(0.044)$ between them.

Testing the three different $K$ values, suggested by the two methods $(47,48)$, revealed that the gazelle population (Gazella gazella) from Hatay had a completely different gene pool than those of Erikçe and Kızılkuyu. This result was expected, as the two captive populations belonged to a different gazelle species than the Hatay population. Before carrying out the analyses, the Kızılkuyu samples were considered as one group of captive population. After the structure analysis, the Ministry was asked about the origins of the distinct individuals (represented by red in the structure plot), and it was understood that some of the samples were obtained from licensed hunters and they were from the wild population of Kızılkuyu (the samples numbered from 1 to 8 and from 10 to 12 in Figure 2). Thus, the power of the admixture analysis is attested by unraveling the fact that some individuals in the population had different source populations. However, a few hunted (wild) individuals, such as the two samples labeled 2 and 11 in Figure 2, seemed to originate from the captive Kızılkuyu population's gene pool (largely purple). It can be speculated that these two individuals might have been released from the Kızılkuyu farm into the wild, before they were hunted. We know that the Ministry had periodically released some individuals from this farm before the hunting seasons. In addition, two individuals (numbered 9 and 13 in Figure 2) of the Kızılkuyu state farm exhibited a different genetic structure than the rest of the Kızılkuyu samples. Presumably, we might label them as the Kızılkuyu wild type. It is possible that, they might have originated from those wild individuals introduced to the Kızılkuyu captive population. As explained in Figure 1, there are individuals taken from the Kıılkuyu wild site and introduced into the Erikçe State Farm, too. The genetically differentiated individuals found in the Erikçe State Farm (labeled 14-16 in Figure 2) could have originated from these introduced wild individuals.
Microsatellite-based $\mathrm{N}_{\mathrm{e}}$ estimations for both the Kızılkuyu and Erikçe populations revealed low numbers (9.7 for Kızılkuyu and 8.9 for Erikçe). These low numbers are observed despite the fact that they are not completely closed populations. Firstly, the state farms are open for individuals found wounded or illegally captured. This results in gene flow into the captive populations from other sources, most probably from the wild populations. Secondly, it is known that three individuals were transported from the Kızılkuyu wild population to the Erikçe farm and six individuals from Ceylanpınar were transported to the Kızılkuyu farm. This also supports the view that they are not totally closed populations. If these estimations are approximately correct, the estimated $\mathrm{N}_{\mathrm{e}}$ (which is 24.5 when we pool the populations) is still much lower than 50 , which is an indicator of a small population size according to the 50/500 rule by Franklin (71) and Soulé (72). This rule claims that a minimum $\mathrm{N}_{\mathrm{e}}$ of 50 is necessary to avoid inbreeding and a minimum $\mathrm{N}_{\mathrm{e}}$ of 500 is necessary to reduce genetic drift. Finally, for the Hatay population, $\mathrm{N}_{\mathrm{e}}$ was estimated as 6.4 , which is very low. This might be due to the low number of individuals $(n=4)$ sampled in this study, or alternatively, this population might indeed have a small $\mathrm{N}_{\mathrm{e}}$. In order to understand the underlying reason, more samples should be analyzed and this estimation should be repeated. The Gazella gazella population in Hatay is the only one existing in Turkey. Therefore, the present diversity must be analyzed before taking conservation actions.

The decreasing birth rates and increasing death rates, observed in the Kızılkuyu and Erikçe populations from the estimated life parameters, probably resulted from inbreeding depression, which is expected when Ne values are very low. Furthermore, in the Erikçe population, lower birth rates and higher death rates than those of the Kızılkuyu population are a good natch for the lower genetic diversity (allelic richness and heterozygosity) observed in the Erikçe population. As can be seen from the graph (Figure 6) for Kızılkuyu, birth and death rates had peaks at the same time after reintroduction/introduction practices (indicated by upward arrows) were carried out. Possibly, after transporting individuals from the state farms, intraspecific competition decreased and therefore the birth rate increased and the death rate decreased. Intraspecific competition might be due to the available space in the state farms rather than the food supply as limited physical space (or crowding) may also cause decreased fecundity, increased mortality in juveniles and post-reproductives due to upsets induced in the endocrine system (73). Furthermore, the introduction of wild Kızılkuyu individuals into the Erikçe State Farm in 2010 and 2011 may have delayed the population collapse until 2014.

The results that should be considered for the conservation studies of Anatolian Gazella marica populations can be summarized as follows: (i) Both of the captive populations have low effective population sizes, and (ii) there is significant divergence between them. (iii) whether the two captive populations' gene pool diverged from the Kızılkuyu wild population must be checked in future studies, urgently), (iii) Both of the captive populations presented signals of inbreeding 
depression, and iv) possibly, they might both be suffering from intraspecific competition. If a corridor is established between the populations (both wild and state farm) of Gazella marica species, it may slow down the diversity loss and genetic drift and thus decrease differentiation from each other. Furthermore, the reason for the possible intraspecific competition can be analyzed and intraspecific competition can be reduced. However, even then, chances are slim that the populations of the present study can ever be used to establish sustainable populations in the wild. Perhaps a better strategy would be to consider exchanges of individuals between the populations of different countries.

\section{CONCLUSION}

The markers employed in this study provides a good means of assessing populations of gazelle species for their species identity, degree of divergences, effective population sizes and for the presence of admixture within the populations. This data would certainly contribute to he development of better strategies in future studies for the conservation of the species.

Peer-review: Externally peer-reviewed.

Author Contributions: Conception/Design of study: E.K.B., H.E., T.H., TK.; Data Acquisition: F.D.S., M.D.O. E.K.B.; Data Analysis/ Interpretation: F.D.S., M.D.O., E.K.B., S.C.A., I.T., H.E., T.H., T.K.; Final Approval and Accountability: F.D.S., M.D.O., E.K.B., S.C.A., I.T., H.E., T.H., T.K.; Drafting Manuscript: F.D.S., M.D.O., E.K.B.; Critical Revision of Manuscript: E.K.B., I.T.; Technical or Material Support: E.K.B., H.E., T.H.; Supervision: E.K.B., I.T.

Conflict of Interest: The authors declare that they have no conflicts of interest.

Financial Disclosure: The project was financially supported by the Scientific and Technological Research Council of Turkey (Project no: KAMAG 109G016).

Acknowledgment: No conflicts of interest related to this study.

\section{References}

1. Groves CP, Grubb P. Ungulate taxonomy. Baltimore, Md.: JHUP; 2011.

2. Lerp H, Wronski T, Plath M, Schröter A, Pfenninger M. Phylogenetic and population genetic analyses suggest a potential species boundary between Mountain (Gazella gazella) and Arabian Gazelles (Gazella arabica) in the Levant. Mamm Biol 2013; 78(5): 383-86.

3. Mallon DP. Gazella subgutturosa. IUCN Red List of Threatened Species. Version 2011.2; 2008.

4. Kasparek M. On the historical distribution and present situation of gazelles, Gazella ssp., in Turkey. Zool Middle East 1986; 1: 11-5.

5. Kumerloeve, H. Die Säugetiere (Mammalia) Syriens und des Libanon. Spixiana 1975b; 18, 159-225.

6. Kumerloeve, H. Bemerkungen zum Gazellen Vorkommen im südöstlichen Kleinasien. Z. Saugetierkd. 1969; 34, 113-20.

7. Kumerloeve, H. Die Säugetiere (Mammalia) der Türkei. Spixiana 1975a; 18, 69-158.

8. Turan N. Game and wildlife of Turkey mammals. Ongun Kardeşler Matbaacılık Sanayii, Turkey; 1984.
9. Tez C, Akalın H, Erkekkardeş M. Additional karyological data on goitered gazelle, Gazella subgutturosa, from Turkey. Arch Biol Sci 2009; 61(1):45-8.

10. Durmuş M. Determination of home range size and habitat selection of gazelles (Gazella subgutturosa) by GPS Telemetry in Şanlıurfa. Middle East Technical University Graduate School of Natural and Applied Sciences, MSc Thesis. 2010.

11. Kumerloeve H. Zur Verbreitung kleinasiatischer Raub- und Huftiere sowie einiger Großnager. Säugetierkd Mitt 1967; 15: 337-409.

12. Turan N. Report on the protection and restoration of gazelle (Gazella subgutturosa) in Turkey. Turkish Department of GameWildlife: 7; 1977.

13. Ölçer SY. Chapter 20: Turkey. Mallon DP, Kingswood SC, compilers. Antelopes Part 4: North Africa, the Middle East, and Asia Global survey and regional action plans SSC Antelope Specialist Group IUCN, Gland, Switzerland and Cambridge, UK; 2001. p.112-13.

14. Çobanoğlu AE. Identification Of Demographic Structure and Population Viability Analysis of Gazella subgutturosa in Şanlıurfa. Middle East Technical University Graduate School of Natural and Applied Sciences, MSc Thesis. 2010.

15. Kankılıç $T$, Özüt $D$, Gürler Ş, Kence $M$, Bozkaya F, Kence $A$. Rediscovery of a new mountain gazelle population and clarification of taxonomic status of the genus Gazella in Turkey using mtDNA sequencing. Folia Zool 2012; 61(2): 129-37.

16. Wronski T, Sandouka M. Plath $M$, Cunningham P. Differences in sexual dimorphism among four gazelle taxa (Gazella spp.) in the Middle East. Anim Biol 2010; (60) 395-412.

17. Hammond RL, Macasero W, Flores B, Mohammed OB, Wacher T, Bruford MW. Phylogenetic Reanalysis of the Saudi Gazelle and Its Implications for Conservation. Conserv. Biol. 2001; 15:1123-33.

18. Wacher T, Wronski T, Hammond RL, Winney B, Blacket MJ, Hundertmark KJ, et al. Phylogenetic analysis of mitochondrial DNA sequences reveals polyphyly in the goitered gazelle (Gazella subgutturosa). Conserv Genet 2011; 12:827-31.

19. Wronski T, Wacher T, Hammond RL, Winney B, Hundertmark KJ, Blacket $\mathrm{MJ}$, et. al. Two reciprocally monophyletic mtDNA lineages elucidate the taxonomic status of Mountain gazelles (Gazella gazella), Syst Biodivers 2010; 8(1): 119-29.

20. Lerp $H$, Wronski $T$, Pfenninger $M$, Plath $M$. A phylogeographic framework for the conservation of Saharan and Arabian Dorcas gazelles (Artiodactyla: Bovidae). Org Divers Evol 2011; 11(4): 31729.

21. Groves $\mathrm{CP}$, Harrison DL. The taxonomy of the gazelles (genus Gazella) of Arabia. J Zool London 1967; 152:381-7.

22. Groves CP. On the smaller gazelles of the Genus Gazella de Blainville, 1816. Z. Saugetierkd. 1969; 37:38-60.

23. Lerp $\mathrm{H}$, Wronski $\mathrm{T}$, Butynski $\mathrm{T}$, Plath $\mathrm{M}$. Speciation of Arabian gazelles. In: Michalak $P$ (ed.) Speciation: Natural Processes, Genetics and Biodiversity. Nova Science Publishers, Hauppauge, NY pp. 59-82; 2013.

24. Oğurlu I. Wild ungulates of Turkey. Ongulés/Ungulates 1992; 91:575-7.

25. Sambrook J, Fritsch EF, Maniatis T. Molecular Cloning: A Laboratory Manual, 2nd ed. Vol. 3, Cold Spring Harbor Laboratory, New York, USA; 1989.

26. Winnepenninckx B, Backeljau T, de Wachter R. Extraction of high molecular weight DNA from molluscs. Trends in Genet 1993; 9 (12): 407.

27. Wilson GA, Strobeck C, Wu L, Coffin JW. Characterization of microsatellite loci in caribou Ranginfer tarandus, and their use in other artiodactyls. Mol Ecol 1997; 6: 697-9. 
28. Toldo S, Fries SR, Steffen P, Neibergs HL, Barendse W. Physically mapped cosmid-derived microsatellite markers as anchor loci on the bovine chromosome. Mamm Genome 1993; 4:720-7.

29. Buchanan FC and Crawford AM. Ovine microsatellites at the OarFCB11, OarFCB128, OarFCB193, OarFCB266 and OARFCB304 loci. Anim Genet 1993; 24: 145.

30. Mommens GW, Coppieters A. Dinucleotide repeat polymorphism at the bovine MM12E6 and MM8D3 loci. Anim Genet 1994; 25: 368.

31. Bishop MD, Kappes SM. A genetic linkage map for cattle. Genetics 1994; 136:619-39.

32. Kappes SM, Keele JW, Stone RT, McGraw RA, Sonstegard TS, Smith TP, et. al. A second-generation linkage map of the bovine genome. Genome Res 1997; 7(3): 235-49.

33. Vaiman D, Mercier D. A set of 99 cattle microsatellites: characterisation, synteny mapping, and polymorphism. Mamm Genome 1994; 5:288-97.

34. Mezzelani A, Zhang Y, Redaelli L, Castiglioni B, Leone P, Williams JL, et. al. Chromosomal localization and molecular characterization of 53 cosmid-derived bovine microsatellites. Mamm Genome 1995; 6(9): 62935.

35. Steffen $P$, Eggen A. Isolation and mapping of polymorphic microsatellites in cattle. Anim Genet 1993; 24: 121-4.

36. Saitbekova N, Gaillard C, Obexer-Ruff G, Dolf G. Genetic diversity in Swiss goat breeds based on microsatellite analysis. Anim Genet 1999; 30 (1): 36-41.

37. Georges M, Massey J. Polymorphic DNA markers in Bovidae. J World Intellect Prop Publ No 92:13120, 1992

38. Kemp SJ, Brezinsky L, Teale AJ. ILSTS002: a polymorphic bovine microsatellite. Anim Genet 1992; 23: 184.

39. Moore SS, Byrne K. Characterisation of 65 bovine microsatellites. Mamm Genome 1994; 5: 84-90.

40. Oosterhout C, Hutchinson WF, Wills DPM, Shipley PF. MicroChecker: software for identifying and correcting genotyping errors in microsatellite data. Mol Ecol Notes 2004; 4:535-8.

41. Excoffier L, Laval G, Schneider S. ARLEQUIN version 3.01: an integrated software package for population genetics data analysis. University of Bern, Institute of Zoology, Switzerland. Available from http://cmpg.unibe.ch/software/arlequin3 2006.

42. Goudet J (2001) FSTAT, A Program to Estimate and Test Gene Diversities and Fixation Indices, Version 2.9.3. http://www.unil.ch/ izea/softwares/fstat.html

43. Sokal RR, Rohlf FJ. Biometry (3rd edn). WH Freman and company: New York; 1995.

44. Kalinowski ST, Taper ML, Marshall TC. Revising how the computer program CERVUS accommodates genotyping error increases success in paternity assignment. Mol Ecol 2007; 16(5): 1099-106.

45. Wright $\mathrm{S}$. The Interpretation of Population Structure by F-Statistics with Special Regard to Systems of Mating. Evolution (N Y) 1965; 19(3):395-420.

46. Pritchard JK, Stephens M, Donnelly P. Inference of population structure using multilocus genotype data. Genetics 2000; 155:94559.

47. Evanno G, Regnaut S, Goudet J. Detecting the number of clusters of individuals using the software structure: a simulation study. Mol Ecol 2005; 14:2611-20.

48. Tapio M, Ozerov M, Tapio I, Toro M, Marzanov N, Cinkulov M, et. al. Microsatellite-based genetic diversity and population structure of domestic sheep in northern Eurasia. BMC Genetics 2010; 11:76.

49. Jakobsson M, Rosenberg NA. CLUMPP: a cluster matching and permutation program for dealing with label switching and multimodality in analysis of population structure. Bioinformatics 2007; 23: 1801-6.
50. Rosenberg NA. DISTRUCT: a program for the graphical display of population structure. Mol. Ecol. Notes 2004; 4: 137-8.

51. Do C, Waples RS, Peel D, Macbeth GM, Tillett BJ, Ovenden JR. Ne Estimator V2: re-implementation of software for the estimation of contemporary effective population size (Ne) from genetic data. Mol Ecol Resour 2014; 14(1): 209-14.

52. Kocher TD, Thomas WK, Meyer A, Edwards SV, Pääbo S, Villablancha FX, et. al. Dynamics of mitochondrial DNA evolution in animals: amplification with conserved primers. PNAS USA 1989; 86: 6196200.

53. Irwin D, Kocher T, Wilson A. Evolution of the cytochrome-b gene of mammals. J Mol Evol 1991; 32: 128-44.

54. Hall TA (2013) BioEdit $\vee$ 7.2. 3. Biological sequence alignment editor for Win 95/98/NT/2K/XP7.

55. Tamura K, Stecher G, Peterson D, Filipski A, Kumar S. MEGA6: molecular evolutionary genetics analysis version 6.0. Mol Biol and Evol 2013; 30(12): 2725-9.

56. Liu WS, Mariani P, Beattie CW, Alexander LJ, De León FAP. A radiation hybrid map for the bovine Y Chromosome. Mamm Genome 2002; 13(6): 320-6.

57. Wright S. Vol. 4: Variability within and among natural populations. Chicago, University of Chicago Press; 1978.

58. Hassanin A, Douzery EJ. The tribal radiation of the family Bovidae (Artiodactyla) and the evolution of the mitochondrial cytochrome b gene. Mol Phylogenet Evol 1999; 13(2): 227-43.

59. Murtskhvaladze M, Gurielidze Z, Kopaliani N, Tarkhnishvili D. Gene introgression between Gazella subgutturosa and $G$. marica: limitations of maternal inheritance analysis for species identification with conservation purposes. Acta Theriol 2012; 57: 383-6.

60. Lerp, H., Wronski, T., Plath, M., Schröter, A., \& Pfenninger, M. Phylogenetic and population genetic analyses suggest a potential species boundary between Mountain (Gazella gazella) and Arabian Gazelles (Gazella arabica) in the Levant. Mamm Biol 2013b; 78(5): 383-86.

61. Hanotte O, Okomo M, Verjee Y, Rege JEO, Teale A. A polymorphic $Y$ chromosome microsatellite locus in cattle. Anim Genet 1997; 28(4): 318-9.

62. Edwards CJ, Dolf G, Looft C, Loftus RT, Bradley DG. Relationships between the endangered Pustertaler-Sprinzen and three related European cattle breeds as analysed with 20 microsatellite loci. Anim Genet 2000; 31: 329-32.

63. Zachos FE, Karami M, Ibenouazi Z, Hartl GB, Eckert I, Kirschning J. First genetic analysis of a free-living population of the threatened goitered gazelle (Gazella subgutturosa). Mamm Biol 2010; 5:27782.

64. Ruiz-Lopez MJ, Roldan ER, Espeso G, Gomendio M. Pedigrees and microsatellites among endangered ungulates: what do they tell us? Mol Ecol 2009; 18(7): 1352-64.

65. Lerp H, Plath M, Wronski T, Bärmann EV, Malczyk A, Resch RR, et al. Utility of island populations in re-introduction programmesrelationships between Arabian gazelles (Gazella arabica) from the Farasan Archipelago and endangered mainland populations. Mol Ecol 2014; 23(8): 1910-22.

66. Hadas L, Hermon D, Boldo A, Arieli G, Gafny R, King R, et. al. Wild Gazelles of the Southern Levant: genetic profiling defines new conservation priorities. PloS One 2015; 10(3).

67. Duo H, Na L, Hong Y, Zhang Y, Li D. Genetic diversity of Przewalski's gazelle using noninvasive DNA and its implications for conservation. AJB 2015; 14(13): 1107-13. 
68. Okada A, Ito TY, Buuveibaatar B, Lhagvasuren B, Tsunekawa A Genetic structure in Mongolian gazelles based on mitochondrial and microsatellite markers. Mamm Biol 2015; 80(15): 303-11

69. Arif IA, Khan HA, Shobrak M, Homaidan AAA, Sadoon MA, Farhan AHA. Measuring the genetic diversity of Arabian Oryx using microsatellite markers: implication for captive breeding. Genes Genet Syst. 2010; 85(2): 141-5.

70. Hildebrand CE, David C, Torney C, Wagner P. Informativeness of polymorphic DNA markers. The Human Genome Project: deciphering the blueprint of heredity. University Science Books, CA, USA,; 1994. p 100-2.
71. Franklin IR. Evolutionary change in small populations. Soulé ME and Wilcox BA, editors. Conservation Biology: an evolutionaryacological perspective, Sunderland: Sinauer; 1980. p 135-50.

72. Soulé ME. Thresholds for survival: maintaining fitness and evolutionary potential, in Conservation Biology: An EvolutionaryEcological Perspective, M. E. Soule and A. Wilcox, Eds.,Sinauer Associates, Sunderland, UK, 1980 p. 151-69

73. Fischer MS and Schliemann H. Volume VIII Mammalia. founded by Kükenthal W, edited by Schmidt-Rhaesa, Andreas W de Gruyter. Handbuch der Zoologie/Handbook of Zoology: Natural History of the Phyla of the Animal Kingdom, Berlin; 2005. 